\title{
ОСОБЕННОСТИ АКТУАЛИЗАЦИИ КОНЦЕПТА САR В РЕЧИ СОВРЕМЕННЫХ АМЕРИКАНСКИХ АВТОМОБИЛИСТОВ
}

\section{PECULIAR FEATURES OF THE CONCEPT CAR ACTUALIZATION IN MODERN SPEECH OF AMERICAN DRIVERS}

Ya. Gimaev

Summary: Aim is to identify the peculiar features of the concept CAR in modern speech of American drivers and compare them to the peculiar features of the corresponding concept in Russian drivers' speech. The functioning of the words that show the peculiar features of the concept CAR is reviewed by the author. The main methods of research are linguistic observation, description, interpretation and conceptual analysis. The lexical and syntactic items representing the concept of a car in public consciousness of Americans is determined. The research results make contribution to the conceptual analysis practice.

Keywords: concept, linguistic view of the world, public linguistic consciousness, anthropomorphism, speech.
Гимаев Ян Айратович

К.филол.н., старший преподаватель, Финансовый университет при правительстве Российской Федерации yan094@mail.ru

Аннотация: Цель статьи - выявление особенностей функционирования концепта САR в речи современных американских автомобилистов и их сравнение с особенностями концепта АВТОМОБИЛЬ в речи российских автомобилистов. Автором осуществлены наблюдения за использованием в речи американских автомобилистов слов, отражающих особенности концепта CAR. При проведении исследования применены методы лингвистического наблюдения, описания, интерпретации результатов и концептуальный анализ. Выявлены лексические и синтаксические средства, с помощью которых создаётся образ автомобиля в массовом сознании американцев. Результаты исследования вносят вклад в практику концептуального анализа.

Ключевые слова: концепт, языковая картина мира, массовое языковое сознание, антропоморфизм, речь.

Я.А. Дидиликэ, В. Вихляев и С. Чарыев, рассматривая языковую репрезентацию концепта АВТОМОБИЛЬ в рекламном дискурсе на английском языке, также приходят к выводу о том, что в рекламных текстах автомобиль регулярно «метафорически представляется как живое существо - человек или животное» [8, с. 212], а Н.В. Данилевская и Вань Нин выделили ключевые смыслы в автомобильных рекламных слоганах, и одним из таких смыслов оказался «Автомобиль - партнёр/друг» [7, с. 191].

Очевидно, что создатели рекламных слоганов опираются на живую речь автомобилистов, потенциальных покупателей. Если бы в массовом сознании владельцев машин изначально не присутствовало концептуальное одушевление автомобилей, реклама сформировать его не смогла бы. В данный момент она лишь использует и расширяет уже готовый образ.

По нашему мнению, одушевление образа автомобиля в речи американцев изучено меньше, чем аналогичное явление в речи отечественных автомобилистов. В связи с этим данный вопрос представляется актуальным и перспективным для исследования.

«Одушевление» машин в речи автомобилистов мы трактуем как результат положительной оценки автомобилей своими владельцами. Такая оценка, безусловно, напоминает нам традицию внимательного отношения к лошадям, помощникам людей. Положительная оценка 
автомобилей возникает не столько благодаря высокой стоимости машин, сколько из-за их незаменимости для многих современных людей. Сегодня автомобили подобно лошадям в прошлых столетиях используются для работы, отдыха, путешествий, демонстрации социального статуса и т.д.

Безусловно, большую роль в актуализации одушевления концепта АВТОМОБИЛЬ / CAR в массовом сознании людей играет современная реклама, стремящаяся возбудить у покупателей автомобилей «чувства привязанности или даже любви к товару, которые могут быть в полной мере направлены только на живой объект» [11, с. 121], или создающая образ автомобиля как «друга или члена семьи» [9, с. 40-41]. Однако смысловой компонент «партнёр / друг» в изучаемом концепте появился не благодаря рекламе и средствам массовой информации, а благодаря положительной оценке объекта.

Данные обстоятельства сформировали и продолжают укреплять в русской лингвокультуре образ автомобиля как большой ценности не только из-за высокой цены, способности помогать в работе и в личных делах, но и благодаря способности быть максимально персонифицированным объектом с набором личностных качеств, характера и т.д.

Нами была выдвинута гипотеза о том, что в массовом сознании более богатых и ранее «автомобилизированных» американцев автомобиль как средство передвижения является меньшей ценностью, а соответствующий концепт в лингвокультуре граждан США занимает не такое важное положение.

Тем не менее, остаётся вопрос, является ли концепт CAR в сознании американцев столь же антропоморфным, как концепт АВТОМОБИЛь в массовом сознании жителей России. Любопытно, прослеживается ли в лингвокультуре жителей США аналогичная преемственность между концептами HORSE и CAR.

Преемственность между концептами CAR и HORSE, безусловно, существовала с момента появления самоходных транспортных средств. Первые автомобили были созданы в англо-американской среде и получили образную связь с лошадьми в виде измерения «мощности автомобильного двигателя в «лошадиных силах» и в определении выносливости автомобиля» [13, с. 87]. Кроме того, вероятно, с отсылкой к образу лошади были даны названия составным частям машины, таким как кузов (the body of a car) или фары (headlights).

Можно отметить, что в 60-х годах XX века в Америке стали появляться так называемые pony cars, «модели легковых автомобилей со спортивным или стилизованным под спортивный дизайном, но, как правило, не имеющие в базовой комплектации мощных двигателей» [16]. Одной из культовых машин этого класса по сей день остаётся Ford Mustang, хотя современные машины этой модели уже не имеют маломощных двигателей и не называются pony cars. Интересен тот факт, что при выборе названия для данной модели в начале 1960-х годов рассматривались варианты Puma, Cheetah (пума, геnард), но «лошадиное» название оказалось более подходящим [17].

Однако в последние десятилетия образная связь между концептами CAR и HORSE не поддерживается новыми языковыми примерами. А вот направленность концепта CAR на человека, его внешность, характер и поведение подтверждается многочисленными примерами в современной разговорной речи.

Нами были рассмотрены высказывания из различных Интернет-форумов автомобилистов США, текстовые обзоры моделей автомобилей на американских сайтах, новостные сообщения. Анализ данных текстов показал, что «одушевление», «очеловечивание» машин в речи американских автомобилистов осуществляется как на лексическом, так и на синтаксическом уровнях, хоть и, возможно, не в такой степени, в какой машины «одушевляются» носителями русского языка.

Говоря о своих автомобилях, американцы могут подобно россиянам использовать синекдоху, выдавая работу отдельных агрегатов за работу машины целиком (глохнет, разогревается), при этом сам автомобиль может хотеть заглохнуть или иметь симптомы / проблемы:

A year ago, I had a problem with my 95 GMC wanting to stall out when warmed up...

My 1994 Chevy 1500 5.7L has the same symptoms. Runs great till it warms up.

My 1992 Suburban had the same exact issue [18].

В речи российских автомобилистов активно используются глаголы, характеризующие машины как одушевлённые существа: автомобиль плетётся как черепаха, прётся, несётся, летит, мчится, уступает дорогу, въехал в столб, подмигивает, ест (жрёт) резину / масло; машины обувают, переобувают и т.д. [5, с. 50]. Употребляя подобные выражения, носитель языка как бы забывает о том, что все эти действия производятся водителем, управляющим транспортным средством, или происходят по законам физики, а сам автомобиль - это лишь орудие или неодушевлённый объект действия человека.

В речи американских автомобилистов мы можем найти лишь немногочисленные глаголы движения, применяемые для характеристики машин, основные значения которых первоначально использовались для наименования действий человека.

Shuffling cars / shuffling of cars - перемещающиеся 
автомобили / перемещение автомобилей на парковке (кем-то) [19]. В этом выражении, на наш взгляд, глагол to shuffle не только выступает в значении перемешивать, maсовать, но и затрагивает смысловой компонент своего первого значения шаркать за счёт звука интенсивного трения колёс об асфальт при парковке. Шаркать - глагол, первоначально обозначающий действие, производимое исключительно людьми в обуви.

The shuffling of cars in and out the garage makes it look like we are holding a Mercedes classic meeting [20].

To yield - уступать (дорогу). В речи англоговорящих автомобилистов не водитель уступает дорогу, а машина уступает дорогу / имеет право проезда / хочет проexamb:

What does yield right-of-way mean?

It means the other car has the right of way, and you must yield to him, let him go in front of you.

You don't have to stop, just slow down enough for him to get on the highway in front of you.

example: if a person wants to cross the street and a car wants to drive by, and a sign says "yield! pedestrians have right of way" then the person crossed before the car drives by [21].

В данном отрывке интересно также то, что для обозначения автомобиля используется личное местоимение him (по правилам грамматики указывающее исключительно на лицо мужского пола), что сближает транспортное средство с человеком в смысловом отношении.

Глагол to barrel в американском английском имеет значение двигаться очень быстро, нестись применительно к человеку. Впоследствии он получил возможность характеризовать действие автомобиля:

Smith barreled into him, knocking him over [22].

Car barreling into restaurant caught on camera [23].

Возможно, с позиций психологии это объясняется тем, что люди, находясь в машине и двигаясь в потоке машин, а также будучи пешеходами не видят других водителей и не знают, кто находится за рулём соседних автомобилей. Машины воспринимаются как живые существа, ведь каждому автомобилисту присущ свой стиль вождения и поведения на дороге. Это касается всех автомобилистов и пешеходов вне зависимости от культурной принадлежности, национальности и языка.

C точки зрения персонализации концепт CAR в американской английской речи менее антропоморфен, чем концепт АВТОМОБИЛЬ в современной русской. Это, по нашему мнению, связано с тем, что в английском языке глаголы движения изначально в большинстве своём способны обозначать действия как одушевлённых, так и неодушевлённых предметов (to go, to move, to run и другие). Да и самой категории одушевлённости / неодушев- лённости в английском языке нет.

Не только действия человека, воспринимаемые как действия автомобиля, являются признаками антропоморфизма соответствующего концепта. Являясь большой ценностью, машина получает множество наименований, подобных именам людей или кличкам животных. В.А. Гурский выделяет разные способы наименования автомобилей [6], но сам факт называния технического транспортного средства индивидуальным именем уже свидетельствует о высокой степени антропоморфизма концепта АВТОМОБИЛЬ / САR.

По нашему мнению, американцы более, чем россияне склонны давать имена своим автомобилям. Исходя из цвета, названия модели или просто используя популярные человеческие имена, преимущественно женские, они называют свои личные транспортные средства. Среди наиболее популярных имён Betsy, Bessie, Betty, Sally, Bertha, Lucy, Fred, Stella [24]. Стоит отметить популярность разговорных названий определённых марок и моделей американских автомобилей: «Cad, Caddy, Caddie, Kittie (для Cadillac); Chevy (для Chevrolet), Pete (для Peterbilt); Lizzie (для фордовской модели «Т»)» [10, с. 13], которые сходны с человеческими именами или создаются по их словообразовательным моделям.

Следует сказать, что в современной речи американских автомобилистов стали использоваться прилагательные, изначально обозначавшие только признаки человека, но вполне способные характеризовать и машину, её отдельные агрегаты или управление.

The brakes are strong [25].

15 Most Beautiful Cars on Sale for 2020 [26].

The great ones offer more engaging handling, better and more responsive steering, and even a manual gearbox [27].

На наш взгляд, подобная метафоричность в современной русской речи проявляется намного сильнее и уже не воспринимается носителями языка как нечто странное. В современной русской лингвокультуре синтагматическими партнёрами существительных машина или автомобиль могут быть прилагательные прекрасный, красивый, надёжный, умный, интеллектуальный, резвый, крутой, дерзкий, неприхотливый, брутальный, агрессивный, выносливый, мужественный, женственный и др. Этот факт объясняется определёнными изменениями в эмоционально-оценочной сфере современного человека, готового решительно реализовывать «намерение дать в тексте / речи оценку всему, о чём повествует, составляет суждение, что описывает, если нечто стало предметом его внимания, вызвало интерес, породило эмоциональную реакцию» [12, с. 289]. А учитывая важное место автомобиля в системе материальных ценностей современных россиян, можно утверждать, что все эти антропоморфные эпитеты являются результатом 
большого внимания и интереса россиян к автомобилям.

Стоит отметить, что в отличие от российских автомобилистов, использующих такие образные слова, как глаза, реснички, губы, бока, улыбка, морда, тапки, задница, ушки для описания внешности машины [5, с. 50], американцы не склонны называть отдельные элементы автомобиля подобными словами. Исключением можно назвать лишь общепринятую международную метафору сердца как двигателя автомобиля:

A pricey special-edition M2 with a 444-hp heart reminds us of the BMWs of the past [28].

Сколько цилиндров может быть у двигателя: сердче машины [29].

В заключении следует признать, что все перечисленные речевые и языковые факты отражают безусловную актуальность изучаемого концепта как в русском, так и в американском языковом сознании. Однако русский кон- цепт имеет более выраженный ценностный компонент. Это проявляется на всех уровнях данного ментального образования, начиная с его названия. Машина (с XIX в. сложный самодвижущийся механизм, поезд) в России воспринималась (а хорошая иностранная машина продолжает восприниматься) как нечто недосягаемое, дорогое. Слово car (первоначально имело значение всего лишь повозки, тележки) же отражало и продолжает отражать в первую очередь функциональную сторону соответствующего концепта.

Однако несмотря на прагматизм, положительную оценку функциональности и утилитарности личных транспортных средств жителями США, речь американских автомобилистов, как и речь российских, демонстрирует антропоморфизм как одушевление или очеловечивание образа машины. Такое очеловечивание является едва ли не ключевой особенностью концепта CAR в современном массовом сознании американцев.

\section{ЛИТЕРАТУРА}

1. Барбун В.В. Аксиологические признаки концепта «автомобиль» в американской и русской лингвокультурах // Вестн. Моск. ун-та. Сер. 9. Филология. 2016. № 5. С. 118-128.

2. Булатникова Е.Н. Концепты «лошадь» и «автомобиль» в русском языке: автореф. дис.. канд. филол. наук. Екатеринбург, 2006. 23 с.

3. Буряковская В.А. Языковая репрезентация автомобиля в современной массовой культуре (на материале Русско- и англоязычного рекламного дискурса) // Вестник ВГУ. Серия: Лингвистика и межкультурная коммуникация. 2013. №1 С.174-177.

4. Бытотова Л.И. Концепт-предшественник и концепт-преемник: «лошадь» и «автомобиль» (на материале русского и хакасского языков) // Филологические науки в России и за рубежом: материалы Междунар. науч. конф. (Санкт-Петербург, февраль 2012 г.). СПб.: Реноме, 2012. С. 110-112.

5. Гимаев Я.А. Особенности актуализации концепта МАШИНА в современном русском языковом сознании // Русский язык в славянской межкультурной коммуникации: история и современность. сборник научных трудов. Москва, 2015. С. 48-52.

6. Гурский В.А. Номинация автомобилей их владельцами // Междунар. студ. науч. вестн. 2015. № 4-4. С. 581-582.

7. Данилевская Н.В., Вань Нин Стилистическое своеобразие автомобильных слоганов: культурологический аспект // Стереотипность и творчество в тексте. Межвузовский сборник научных трудов. Под ред. М.П. Котюровой. - Пермь: Издательство: Пермский государственный национальный исследовательский университет, 2016. С. 187-200.

8. Дидиликэ Я.А., Вихляев В., Чарыев С. Языковая репрезентация концепта «автомобиль» в информационных и рекламных жанрах массмедиа (на материале английского языка) // Фундаментальные и прикладные научные исследования: актуальные вопросы, достижения и инновации. Пенза: Наука и Просвещение, 2016. С. 211-213.

9. Ивинских М.П. Когнитивная метафора в рекламе автомобилей // Проблемы романо-германской филологии, педагогики и методики преподавания иностранных языков. Пермь: Перм. гос. гуманит.-пед. ун-т, 2014. С. 39-42.

10. Коротаева И.Э. Лексико-семантическое поле «Транспорт» в американском варианте английского языка (лингвокультурологический и переводческий аспекты): автореф. дис.. канд. филол. наук. М, 2004. 22 с.

11. Кузнецова М.А. Метафора и метонимия в рекламных слоганах как способ концептуализации образа автомобиля // Фундаментальные и прикладные исследования в современном мире. СПб.: Информ. издат. учеб.-науч. центр «Стратегия будущего», 2016. С. 119-122.

12. Леденёва В.В. Омонимы-эвфемизмы бюджетно в современной речи: коммуникативный, прагматический, словообразовательный аспекты // Актуальные проблемы современного языкознания и методики преподавания языка: сборник материалов Международной научно-практической конференции, посвящённой 120-летию со дня рождения профессора Ивана Александровича Фигуровского. Елец: Елецкий государственный университет им. И.А. Бунина, 2019. С. 289-295.

13. Рогалева 0.С. Метафорическая репрезентация автомобиля в современном медийном дискурсе (на примере журнала «За рулем») // Концептуальные исследования в современной лингвистике: сб. науч. тр. - СПб.: Горловка, 2010. - С. 85-88.

14. Румеус Н.А. Уподобление автомобиля живому существу: 300- и антропоморфные образы русской языковой картины мира (обзор публикаций) // Вестник Омского государственного педагогического университета. Гуманитарные исследования. 2019. № 4 (25). С. 84-86.

15. Румеус Н.А., Федяева Н.Д. Антропоморфность образа автомобиля в русской языковой картине мира: анализ семантико-структурных моделей // Коммуникативные исследования. 2020. Т. 7. № 3. С. 627-638. 
16. https://ru.wikipedia.org/wiki/Pony_Car (дата обращения: 28.02.2021).

17. https://ru.wikipedia.org/wiki/Ford_Mustang (дата обращения: 28.02.2021).

18. https://www.cargurus.com/Cars/Discussion-c2021_ds530318 (дата обращения: 28.02.2021).

19. https://dictionary.cambridge.org/dictionary/english-russian/shuffle?q=shuffling (дата обращения: 28.02.2021).

20. https://www.reddit.com/r/mercedes_benz/comments/6bb04w/the_shuffling_of_cars_in_and_out_the_garage_makes/ (дата 0бращения: 28.02.2021).

21. https://answers.yahoo.com/question/index?qid=20080720131549AAyoS0q (дата обращения: 28.02.2021).

22. https://www.Idoceonline.com/dictionary/barrel (дата обращения: 28.02.2021).

23. https://edition.cnn.com/videos/us/2017/01/06/car-drives-into-restaurant-hln-banfield.hln (дата обращения: 28.02.2021).

24. https://www.thrillist.com/cars/nation/the-most-popular-car-names-in-america-what-your-vehicles-name-says-about-you (дата 0бращения: 28.02.2021).

25. https://www.edmunds.com/kia/telluride/ (дата обращения: 28.02.2021).

26. https://www.caranddriver.com/features/g15383134/most-beautiful-cars/\#sidepanel (дата обращения: 28.02.2021).

27. https://www.caranddriver.com/reviews/a35556489/2021-infiniti-q60-red-sport-400-awd-drive/ (дата обращения: 28.02.2021).

28. https://www.caranddriver.com/reviews/a35535010/2020-bmw-m2-cs-by-the-numbers/ (дата обращения: 28.02.2021).

29. https://zen.yandex.ru/media/popmech.ru/skolko-cilindrov-mojet-byt-u-dvigatelia-serdce-mashiny-5edc8fe2b9e66247de83сеес (дата обращения: 28.02.2021).

(с) Гимаев Ян Айратович (yan094@mail.ru).

Журнал «Современная наука: актуальные проблемы теории и практики»

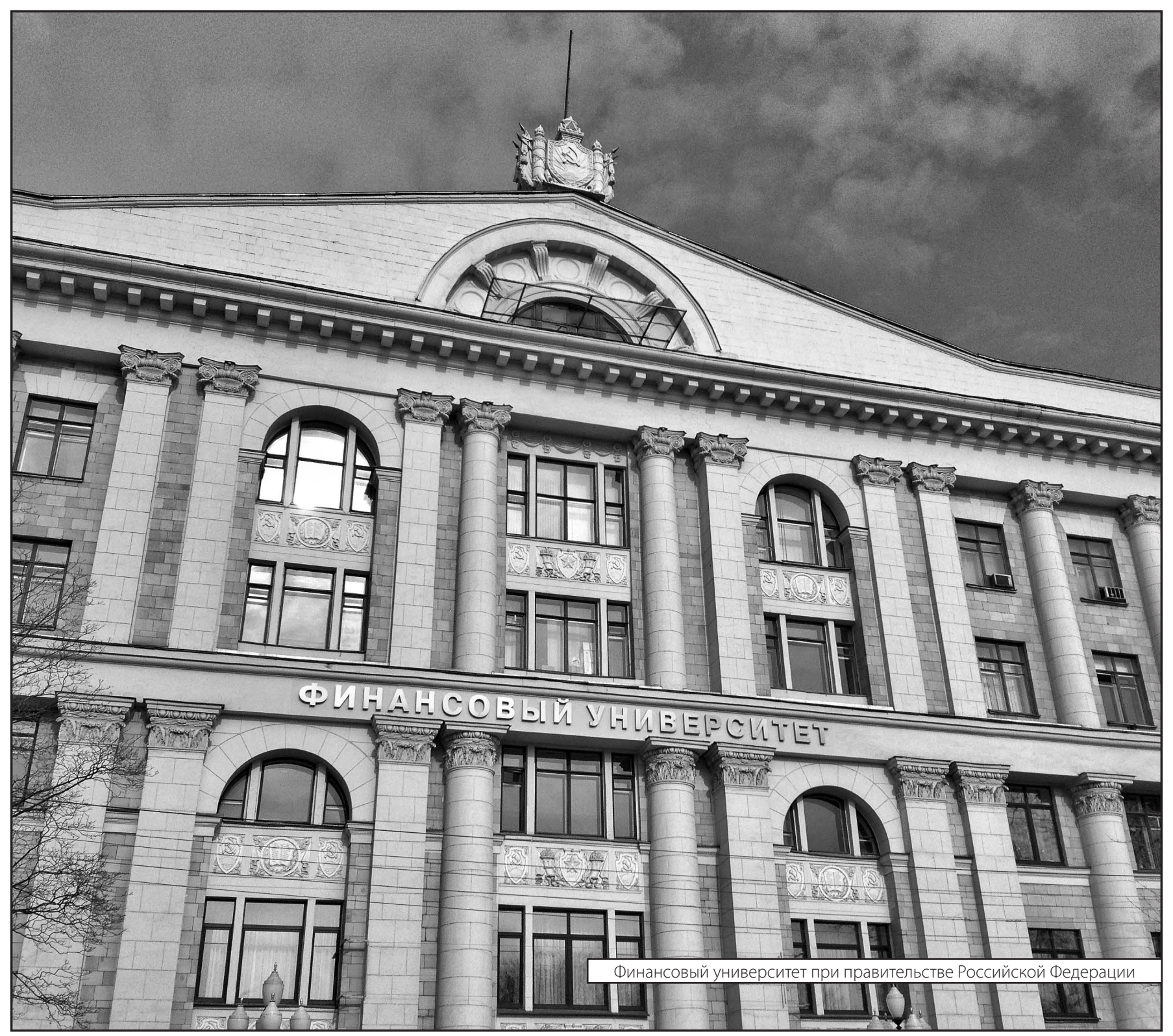

